\title{
Nephroprotective Effect of Functional Beverage of Dolichous Biflorus Seeds on Ethylene Glycol Induced Urolithiasis: A Mechanistic Approach
}

\author{
Ravi Kant ${ }^{1}$, Thakur Gurjeet Singh ${ }^{1, * \text { iD }}$ \\ 1 Chitkara College of Pharmacy, Chitkara University, Rajpura, Punjab, India \\ * Correspondence:gurjeet.singh@ @ chitkara.edu.in (T.G.S.);
}

Scopus Author ID 27667828700

Received: 2.08.2021; Revised: 20.09.2021; Accepted: 24.09.2021; Published: 02.11.2021

\begin{abstract}
Calcium oxalate is the most common type of urolithiasis and is suggested due to membrane oxalate transporters dysfunction. This study has used Dolichos biflorus seeds as a functional beverage to explore its bioactive substances' role on membrane transporters for managing urolithiasis. Urolithiasis model of ethylene glycol induced calcium oxalate crystals in albino Wistar rats was used in this study. Treatment of functional beverage of Dolichos biflorus seeds restored normal blood and urinary oxalate and citrate level and showed anti-urolithiasis activity. Probenecid, a membrane organic anion transporter (Slc26) inhibitor, treatment has abolished anti-urolithiasis activity of functional beverage and suggested Dolichos biflorus produce effect through the restoration of membrane oxalate transporters activity. An oxalate-less diet did not significantly reduce urinary, and plasma oxalate in probenecid treated animals and suggested that dietary oxalate is not primarily involved in calcium oxalate urolithiasis and conditions like hyperoxalemia and hyperoxaluria. Therefore, our findings suggested that endogenous oxalate in conjunction with idiopathic or chronic reduced activity or defective Slc26 transporters due to aging results in calcium oxalate kidney stones. The functional beverage of Dolichos biflorus seeds exhibited anti-urolithiasis activity through improving the activity of Slc26 transporters.
\end{abstract}

Keywords: Dolichos biflorus;calcium oxalate;urolithiasis;anti-urolithiasis;functional beverage; membrane transporters.

(C) 2021 by the authors. This article is an open-access article distributed under the terms and conditions of the Creative Commons Attribution (CC BY) license (https://creativecommons.org/licenses/by/4.0/).

\section{Introduction}

Urolithiasis afflicts around $19 \%$ of the Asian population with a variable recurrence rate, 21 to $53 \%$ [1]. Recurrence of renal stones treatments may eventually lead to deterioration of renal function [2]. Calcium oxalate $(75 \%-90 \%)$ is the most common type of stone afflicts the Asian population, and its proportion has increased in the countries like China, Japan, India, and Indonesia [1]. Oxalate is known as a metabolic end-product (largely produced by the liver and less likely absorbed from food) handled by membrane oxalate transporters [3]. Recent studies in Slc26 transporter knockout mice reported manifestation of hyperoxalemia, hyperoxaluria, and calcium oxalate urolithiasis and suggested pathophysiological role of membrane oxalate transporters dysfunction [4]. A study on 114 idiopathic calcium oxalate urolithiasis patients suggested an inheritable malfunctioning in oxalate membrane transport in stone cases [5]. Pharmacological and Interventional therapeutic procedures do not overcome the risk of stone recurrence, and therapy like ESWL may also be associated with many serious adverse effects, including hypertension, renal damage, and impaired functioning [6]. A few years back, medicinal plants were proposed for better 
management of urolithiasis [7]. To date, plenty of research has been done in this discipline but could not provide satisfactory results. All together, few adverse events are reported with the use of compounds extracted from medicinal plants [8,9]. With the recent developments in nutrition science, it was suggested as "Let functional food be thy medicine" [10], and thus, there is a requirement to switch from the nutritional aspect of food to functional foods as forms of dietary therapy to cure diseases [11]. In Indian traditional medicine, seeds of Dolichos biflorus (used as food pulse known as kultha/kulthi/horse gram) are traditionally used to treat urolithiasis $[12,13]$ along with the treatment of urolithiasis [with urinary diseases.

Dolichos biflorus seeds are a rich source of various natural bioactive substances and can treat various diseases [14]. Although a definite mechanism of Dolichos biflorus seeds is yet to be explored, we planned this study and used Dolichos biflorus seeds as a functional beverage to explore the role of bioactive substances of Dolichos biflorus seeds on membrane transporters for managing hyperoxalemia, hyperoxaluria, and calcium oxalate urolithiasis. We added dietary compounds to prepare an aqueous extract of beverages to make it more palatable due to their analgesic, diuretic, and antioxidant properties. Ocimum tenuiflorum L. is also known as Holy Basil, and its use as an analgesic, antispasmodic, antimicrobial, and immunomodulator is also mentioned in Charak Samhita and Susruta Samhita, the oldest Indian medical texts [15, 16]. The Ayurvedic Pharmacopeia of India and various studies showed the use of Phyllanthus emblica L., Withania somnifera, Green tea, and Foeniculum vulgare Mill. as diuretic and antioxidant and therapeutically indicated for the treatment of urolithiasis [17-22]. Stevia rebaudiana and its non-nutritive, natural sweetener properties were reported for its antioxidant and renoprotective activities in preclinical and clinical settings [23-24]. Therefore, we used a blend of dietary compounds to possess diuretic, analgesic, antispasmodic, antimicrobial, antioxidant, and renoprotective activities of study formulation and favorable for the treatment of urolithiasis as per Ayurvedic Pharmacopeia of India and reported literature.

We employed this legume with other dietary compounds as a functional beverage in the form of tea bags, as tea is a widely consumed beverage worldwide [25]. Functional beverages are an important part of our daily lives and still remain as easily accessible products to get hydration and help manage urolithiasis [26].

\section{Materials and Methods}

\subsection{General experimental procedure.}

All the chemicals and solutions used for the present study were of analytical grade, and reagents were prepared fresh before use. All constituents of Dolichos biflorus seeds-based functional beverages were collected from Dehradun, Uttarakhand. The voucher specimen of all constituents: Dolichos biflorus (seeds- voucher no. 0443), Phyllanthus emblica L. (dried fruitvoucher no. 0924), Ocimum tenuiflorum L. (dried leaves- voucher no. 0773), Green Tea: (dried leaves- voucher no. 0331), Withania somnifera (dried root powder- voucher no. 0578), Foeniculum vulgare Mill. (Seed's powder- voucher no. 0808) and Stevia rebaudiana (dried leaves- voucher no. 0511) was fixed into herbarium sheet, authenticated by a registered plant taxonomist, and deposited at the department of botany, Sri Venkateshwara University, Tirupati, Andra Pradesh and College of Pharmacy, Chitkara University, Rajpura. The constituents of the study formulation were powdered and passed through a mesh 60, and stored in an airtight container before extraction. 


\subsection{Preparation of functional beverage $(F B)$.}

Each $2 \mathrm{~g}$ tea bag was constituted of: moderately coarse powder of Dolichos biflorus (seeds) (1.2 g), Phyllanthus emblica L. (dried fruit) (0.2 g), Ocimum tenuiflorum L. (dried leaves) (0.2 g), Green Tea: (dried leaves) (0.16 g), Withania somnifera (dried root powder) (0.1 g), Foeniculum vulgare Mill. (Seed's powder) $(0.1 \mathrm{~g})$ and Stevia (dried leaves) $(0.04 \mathrm{~g})$. The filled tea bag was dipped in $250 \mathrm{ml}$ hot water (temperature $100^{\circ} \mathrm{C}$ ) for 10 minutes. Teabag was removed after 10 minutes, and aqueous extract was allowed to cool (at room temperature), filtered with filter paper, and used for anti-urolithiasis activity.

\subsection{Animals.}

Antiurolithiasis activity of Dolichos biflorus based functional beverage was evaluated in albino Wistar rats using ethylene glycol induced urolithiasis model. Male Wistar rats weighing around 200-250 g were obtained from the animal house of College of Pharmacy, Chitkara University, Rajpura. The study protocol and all the experimental procedures used in this study were approved by the Institutional Animal Ethics Committee under registration number 1181/PO/ReBi/s/08/CPCSEA. The animals were kept in cages of polypropylene and maintained under standardized conditions (temperature $27^{\circ} \mathrm{C} \pm 1{ }^{\circ} \mathrm{C}$, humidity $60 \% \pm 4 \%$, and natural dark and light cycles), fed with diet and water as per protocol. The rats were divided into the following groups, comprising of six animals in each group. Vehicle control served as the control regimen and received vehicle only along with regular food and drinking water. The remaining groups received urolithiasis inducing treatment till the 28th day, comprising ethylene glycol $(1 \% \mathrm{w} / \mathrm{v})$ with ammonium chloride $(1 \% \mathrm{w} / \mathrm{v})$ for initial 4 days, followed by ethylene glycol $(1 \% \mathrm{w} / \mathrm{v})$ alone in drinking water. The urolithiasis control group received calcium oxalate crystals-inducing treatment till the 28th day. Cystone group served as the standard regimen and received the anti-urolithiasis drug, cystone $(500 \mathrm{mg} / \mathrm{kg}$, po, OD), from the 15th day till the 28th day. Dolichos biflorus group received FB ( $2 \mathrm{ml}$ po, TID) from the 15th day till the 28th day, and the Thiazide group received hydrochlorothiazide diuretics $(200 \mathrm{mg} / \mathrm{kg}$, OD) from the 15th day till 28 th day. Probenecid groups (on regular and oxalate-free diets) received probenecid (100 $\mathrm{mg} / \mathrm{kg} \mathrm{ip}, \mathrm{OD}$ ) from the 15 th day till the 28th day. In other groups (on regular diets and oxalate-free diets), probenecid (100 $\mathrm{mg} / \mathrm{kg} \mathrm{ip}$, OD) was administered along with FB ( $2 \mathrm{ml}$ po, TID) from the 15 th day till the 28th day.

\subsection{Collection and analysis of urine.}

After 28 days of treatment, all rats were placed in individual metabolic cages with free access to drinking water but without food. Urine samples were collected for 24 hours. The urine volume of each animal was measured. The urine sample of each animal was centrifuged at $2500 \mathrm{~g}$ for 15 minutes. In the supernatant, total urinary excretion of oxalate, citrate, calcium, phosphorous, and creatinine was measured by various biochemical kits (Magus Chemicals, Mohali, India) according to the manufacturer's guidance (12).

\subsection{Serum analysis.}

On the 29th day, each rat was anesthetized with diethyl ether, and the blood sample was collected retro-orbitally; thereafter, animals were sacrificed by cervical decapitation. Serum was separated by centrifugation at $10,000 \mathrm{~g}$ for $5 \mathrm{~min}$ and stored at $-20^{\circ} \mathrm{C}$, until analysis. Various blood parameters, oxalate, and citrate, including serum parameters such as phosphorous, calcium, urea, 
and creatinine, were analyzed by using various biochemical kits (Magus Chemicals, Mohali, India) according to the manufacturer's guidance [12].

\subsection{Histopathological study of kidney.}

The abdomen of the animal was cut, and both kidneys were removed. After isolation, kidneys were cleaned with phosphate buffer saline (ice-cold). The kidney of animals was dissected and fixed in $10 \%$ neutral buffered formalin and processed in a sequential manner with graded alcohol and xylene, and in the end, embedded in paraffin wax. Histological sections of about $5 \mu \mathrm{m}$ thickness were prepared by microtomy and stained with hematoxylin-eosin (H\&E) dye for histological examination. Histological slides were analyzed under a light microscope at 10x magnification. The various histological changes such as hemorrhages, congestion, tubular swelling, vacuolar changes in the cytoplasm, and interstitial fibrosis were observed to check changes in the kidney.

\subsection{CaOx crystals in urine.}

Urine samples were collected on 28 days from each group. One drop of urine was placed on a glass slide for observation of $\mathrm{CaOx}$ crystals using a light microscope [12].

\subsection{Biochemical estimations.}

The isolated kidney was rinsed with isotonic saline (ice-cold) followed by tissue homogenized by centrifugation at 2,000 $\times \mathrm{g}$ for $15 \mathrm{~min}$, and the supernatant was used for biochemical analysis. The oxidative stress markers and antioxidant properties were assessed using standard methods for Thiobarbituric Acid Reactive Substance (TBARS), Reduced Glutathione (GSH), catalase, and SOD activity in homogenized kidney tissue [27].

\subsection{Phytochemical and physicochemical analysis.}

The phytochemical analysis and physical constants such as total ash value, loss on drying, and soluble extractive values were determined per the standard methods described in Ayurvedic Pharmacopoeia of India (Tables 3-6).

\subsection{Statistical Analysis}

Values were expressed in terms of mean \pm standard error mean. Differences among data were determined using a one-way ANOVA test followed by Tukey's multiple comparison test (GraphPad Software, Inc., version 6, CA, USA), and $\mathrm{P}<0.05$ was considered statistically significant.

\section{Results}

\subsection{Effect on plasma biochemical parameters.}

Aqueous functional beverage of Dolichos biflorus (FB) $(\mathrm{p}<0.0001)$ and cystone $(\mathrm{p}<0.0001)$ significantly increased citrate level in blood as compared to urolithiasis control and hydrochlorothiazide treated group. However, there was no statistically significant difference between the new Dolichos biflorus and cystone treated groups for citrate level in the blood(Table 1). The FB $(\mathrm{p}<0.0001)$ and cystone $(\mathrm{p}<0.0001)$ significantly reduced oxalate levels in the blood as compared to the urolithiasis control and hydrochlorthiazide treated group. However, there was no 
statistically significant difference between FB and cystone treated groups for oxalate levels in the blood (Table 1). The inhibitor of Slc26a6 transporter, probenecid treatment, has antagonized the effect of FB on the restoration of the normal level of citrate $(p<0.0001)$ and oxalate $(p<0.0001)$ in blood. The oxalate-free diet alongwith probenecid with and without FB could not restore the normal level of citrate and oxalate in the blood. These findings indicated dietary oxalate content did not significantly contribute to hyperoxaluria and/or hyperoxalemia. The impairment in oxalate excretion through the Slc26a6 transporter could be the possible reason for increased urinary oxalate level followed by urolithiasis. Thus, treatment of FB restores the functioning of the Slc26a6 transporter at the intestinal and renal system and thereby restores the normal oxalate level in the blood (Table 1). FB and cystone did not significantly affect blood calcium, creatinine, phosphorous, and urea compared to vehicle and urolithiasis control and hydrochlorothiazide treated group (Table 1).

Table 1. Effect on serum biochemical parameters.

\begin{tabular}{|c|c|c|c|c|c|c|c|c|c|}
\hline & $\begin{array}{l}\text { Vehicle } \\
\text { Control }\end{array}$ & $\begin{array}{l}\text { Urolithiasis } \\
\text { Control }\end{array}$ & $\begin{array}{l}\text { Cystone } \\
\text { Treated }\end{array}$ & $\begin{array}{l}\text { Thiazide } \\
\text { Treated }\end{array}$ & $\begin{array}{c}\text { Functional } \\
\text { Beverage } \\
\text { Group }\end{array}$ & $\begin{array}{c}\text { Probenecid } \\
\text { Treated }\end{array}$ & $\begin{array}{c}\text { Probenecid } \\
\text { + FB } \\
\text { Treated }\end{array}$ & $\begin{array}{c}\text { Probenecid } \\
\text { +oxalate } \\
\text { free diet } \\
\text { Treated }\end{array}$ & $\begin{array}{c}\text { Probenecid } \\
+ \text { FB + } \\
\text { Oxalate } \\
\text { free diet } \\
\text { Treated }\end{array}$ \\
\hline $\begin{array}{c}\text { Oxalate } \\
(\mu \mathrm{mol} / \mathrm{L})\end{array}$ & $16.16 \pm 1.70$ & $61.83 \pm 3.52$ & $18.00 \pm 3.05^{\mathrm{a}}$ & $59.50 \pm 5.17$ & $16.33 \pm 1.54^{\mathrm{a}}$ & $72.83 \pm 5.10^{\mathrm{b}}$ & $63.66 \pm 6.81^{b}$ & $56.33 \pm 5.23^{b}$ & $46.83 \pm 5.62^{b}$ \\
\hline $\begin{array}{c}\text { Citrate } \\
(\mu \mathrm{mol} / \mathrm{L})\end{array}$ & $133.00 \pm 3.72$ & $78.33 \pm 3.34$ & $125.16 \pm 6.88^{a}$ & $87.00 \pm 5.30$ & $130.50 \pm 5.25^{\mathrm{a}}$ & $76.83 \pm 4.79$ & $83.83 \pm 5.13^{b}$ & $78.33 \pm 4.30^{\mathrm{b}}$ & $86.16 \pm 6.74^{b}$ \\
\hline $\begin{array}{l}\text { Calcium } \\
\text { (mg/dL) }\end{array}$ & $9.16 \pm 0.94$ & $10.33 \pm 0.88$ & $9.50 \pm 0.67$ & $11.50 \pm 1.43$ & $9.50 \pm 0.88$ & $10.00 \pm 0.57$ & $11.08 \pm 0.66$ & $9.86 \pm 0.77$ & $9.98 \pm 0.77$ \\
\hline $\begin{array}{c}\text { Creatinine } \\
(\mathbf{m g} / \mathbf{d L})\end{array}$ & $0.46 \pm 0.08$ & $1.98 \pm 0.21$ & $0.45 \pm 0.09$ & $0.35 \pm 0.07$ & $0.55 \pm 0.10$ & $1.10 \pm 0.23$ & $1.33 \pm 0.21$ & $1.31 \pm 0.20$ & $1.25 \pm 0.20$ \\
\hline $\begin{array}{c}\begin{array}{c}\text { Phosphorous } \\
(\mathbf{m g} / \mathbf{d L})\end{array} \\
\end{array}$ & $8.83 \pm 0.70$ & $6.96 \pm 0.82$ & $7.83 \pm 0.94$ & $8.00 \pm 0.89$ & $8.16 \pm 0.60$ & $7.50 \pm 0.99$ & $8.38 \pm 1.04$ & $8.56 \pm 1.06$ & $9.15 \pm 1.04$ \\
\hline $\begin{array}{c}\text { Urea } \\
(\mathrm{mg} / \mathrm{dL})\end{array}$ & $13.66 \pm 1.11$ & $13.01 \pm 1.22$ & $11.66 \pm 1.11$ & $10.66 \pm 1.02$ & $10.33 \pm 0.49$ & $12.66 \pm 0.88$ & $13.43 \pm 0.86$ & $13.08 \pm 1.36$ & $12.98 \pm 1.05$ \\
\hline
\end{tabular}

\subsection{Effect on urinary biochemical parameters.}

\subsubsection{Urinary citrate excretion.}

FB $(p<0.001)$ and cystone $(p<0.01)$ significantly increased the urinary level of citrate compared to urolithiasis control and the hydrochlorothiazide treated group. However, there was no statistically significant difference between FB and cystone treated groups for urinary citrate levels. The probenecid treatment antagonized $(\mathrm{p}<0.01)$ the beneficial effect of FB on urinary citrate level (Table 2).

\subsubsection{Urinary oxalate excretion.}

FB $(p<0.0001)$ and cystone $(p<0.0001)$ significantly reduced urinary oxalate levels as compared to the urolithiasis control and hydrochlorothiazide treated group. However, there was no statistically significant difference between FB and cystone treated groups for urinary oxalate levels. The probenecid treatment antagonized $(\mathrm{p}<0.0001)$ the beneficial effect of FB on urinary oxalate level (Table 2).

\subsubsection{Urinary calcium excretion:}

FB $(\mathrm{p}<0.01)$ and cystone $(\mathrm{p}<0.05)$ significantly increased urinary calcium levels compared to the urolithiasis control group. However, there was no statistically significant difference between 
FB, cystone, and hydrochlorothiazide treated groups for urinary calcium levels. However, probenecid treatment did not antagonize the beneficial effect of FB on urinary calcium levels (Table 2). Also, the administration of oxalate free diet with probenecid did not further reduce urinary and blood oxalate levels in animals treated with or without FB. This also supports that endogenous oxalate instead of dietary oxalate contributes to the primary source of oxalate in the body. Therefore, low oxalate or oxalate-free diet is less likely to contribute to urolithiasis management (Table 2). FB and cystone did not significantly affect urinary creatinine, phosphorous, and volume compared to the urolithiasis control and hydrochlorothiazide treated group (Table 2). Therefore, the aqueous functional beverage of Dolichos biflorus (FB) was found to be equieffective to cystone, which is a clinically established treatment of urolithiasis.

Table 2. Effect on urinary biochemical parameters.

\begin{tabular}{|c|c|c|c|c|c|c|c|c|c|}
\hline & $\begin{array}{l}\text { Vehicle } \\
\text { control }\end{array}$ & $\begin{array}{c}\text { Urolithiasis } \\
\text { control }\end{array}$ & $\begin{array}{l}\text { Cystone } \\
\text { treated }\end{array}$ & $\begin{array}{l}\text { Thiazide } \\
\text { treated }\end{array}$ & FB Group & $\begin{array}{c}\text { Probenecid } \\
\text { treated }\end{array}$ & $\begin{array}{l}\text { Probenecid } \\
\quad+\text { FB }\end{array}$ & $\begin{array}{c}\text { Probenecid } \\
\text { +oxalate } \\
\text { free diet }\end{array}$ & $\begin{array}{c}\text { Probenecid } \\
+ \text { FB + } \\
\text { oxalate free } \\
\text { diet } \\
\end{array}$ \\
\hline $\begin{array}{c}\text { Oxalate } \\
(\mu \mathrm{mol} / \mathrm{L})\end{array}$ & $238.2 \pm 18.93$ & $2881 \pm 259.5$ & $460.5 \pm 53.63^{\mathrm{a}}$ & $2489 \pm 197.8$ & $331.8 \pm 43.09^{\mathrm{a}}$ & $2407 \pm 212.6^{\mathrm{b}}$ & $2880 \pm 146.4^{\mathrm{b}}$ & $2511 \pm 200.7^{b}$ & $2566 \pm 230.4^{\mathrm{b}}$ \\
\hline $\begin{array}{c}\text { Citrate } \\
(\mu \mathrm{mol} / \mathrm{L})\end{array}$ & $4.53 \pm 0.20$ & $2.48 \pm 0.32$ & $4.21 \pm 0.46^{\mathrm{a} 2}$ & $3.31 \pm 0.26$ & $4.78 \pm 0.28^{\mathrm{a} 1}$ & $3.43 \pm 0.26$ & $3.35 \pm 0.27$ & $3.03 \pm 0.34^{\mathrm{b} 1}$ & $3.05 \pm 0.25^{\mathrm{b} 1}$ \\
\hline $\begin{array}{c}\text { Calcium } \\
(\mu \mathrm{mol} / \mathrm{L})\end{array}$ & $1.4 \pm 0.14$ & $0.10 \pm 0.02$ & $1.56 \pm 0.23^{\mathrm{a} 3}$ & $1.00 \pm 0.16^{\mathrm{a} 3}$ & $1.61 \pm 0.19^{\mathrm{a} 2}$ & $1.48 \pm 0.19^{\mathrm{a} 3}$ & $1.15 \pm 0.27$ & $1.22 \pm 0.35$ & $1.50 \pm 0.30$ \\
\hline $\begin{array}{c}\text { Magnesium } \\
(\mathrm{mmol} / \mathrm{L})\end{array}$ & $3.23 \pm 0.22$ & $6.35 \pm 0.34$ & $3.30 \pm 0.35^{\mathrm{a}}$ & $2.68 \pm 0.21^{\mathrm{a}}$ & $3.13 \pm 0.31^{\mathrm{a}}$ & $6.21 \pm 0.36^{b}$ & $5.05 \pm 0.39^{\mathrm{b} 3}$ & $5.41 \pm 0.55^{\mathrm{b} 1}$ & $5.63 \pm 0.40^{\mathrm{b} 2}$ \\
\hline $\begin{array}{c}\text { Creatinine } \\
(\mathbf{m m o l} / \mathbf{L})\end{array}$ & $4.35 \pm 0.28$ & $3.55 \pm 0.55$ & $3.96 \pm 0.44$ & $4.18 \pm 0.34$ & $3.95 \pm 0.31$ & $4.21 \pm 0.43$ & $4.18 \pm 0.41$ & $4.30 \pm 0.41$ & $4.43 \pm 0.27$ \\
\hline $\begin{array}{c}\text { Phosphate } \\
(\mathrm{mmol} / \mathrm{L})\end{array}$ & $14.88 \pm 0.99$ & $16.35 \pm 1.31$ & $16.20 \pm 0.90$ & $17.08 \pm 1.60$ & $14.88 \pm 1.06$ & $16.43 \pm 1.09$ & $16.87 \pm 1.80$ & $15.77 \pm 1.32$ & $17.30 \pm 1.77$ \\
\hline $\begin{array}{c}\text { Volume } \\
\text { (ml/24 } \\
\text { hours) }\end{array}$ & $29.27 \pm 1.32$ & $27.48 \pm 1.97$ & $25.57 \pm 2.02$ & $28.40 \pm 0.70$ & $29.52 \pm 1.52$ & $26.17 \pm 2.04$ & $25.32 \pm 1.96$ & $27.07 \pm 2.11$ & $26.55 \pm 1.51$ \\
\hline
\end{tabular}

${ }^{\mathrm{a}} \mathrm{p}<0.0001$ vs Urolithiasis control; ${ }^{\mathrm{a} 1} \mathrm{p}<0.001$ vs Urolithiasis control; ${ }^{\mathrm{a} 2} \mathrm{p}<0.01$ vs Urolithiasis control; ${ }^{\mathrm{a} 3} \mathrm{p}<0.05 \mathrm{vs}$ Urolithiasis control; ${ }^{b} \mathrm{p}<0.0001$ vs Functional Beverage Group; ${ }^{b 1} \mathrm{p}<0.01$ vs Functional Beverage Group; ${ }^{b 2} \mathrm{p}<0.001$ vs Functional Beverage Group; ${ }^{b 3} \mathrm{p}<0.05$ vs Functional Beverage Group;Values are expressed as Mean \pm SEM; N=6

\subsection{Effect on kidney tissue biochemical parameters.}

FB and cystone significantly reduced TBARS $(\mathrm{p}<0.001)$ and increased GSH $(\mathrm{p}<0.001)$, catalase $(p<0.001)$, and SOD $(p<0.001)$ activity in homogenized kidney tissue as compared to urolithiasis control and hydrochlorothiazide treated group.

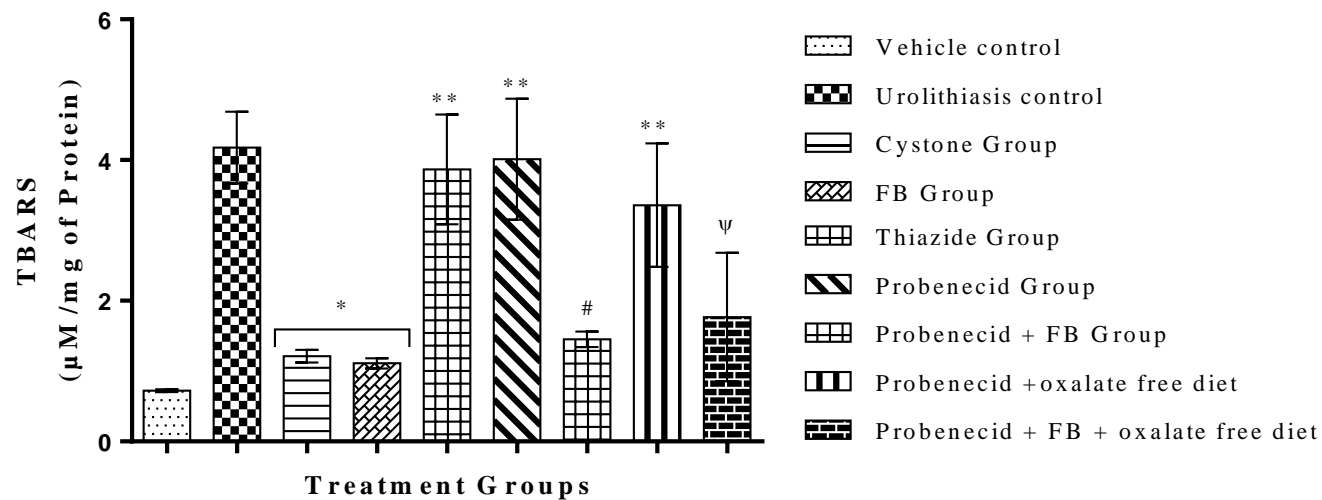

Figure 1. Effect on TBARS level in kidney tissues. ${ }^{*}<<0.001$ vs. Urolithiasis control; ${ }^{*} \mathrm{p}<0.01$ vs. Urolithiasis control; ${ }^{\Psi} \mathrm{p}<0.05$ vs. Urolithiasis control; ${ }^{* *} \mathrm{p}<0.05$ vs. FB Group; Values are expressed as Mean $\pm \mathrm{SEM} ; \mathrm{N}=6$. 
However, there was no statistically significant difference between FB and cystone treated groups for tissue levels of TBARS, GSH, catalase, and SOD (Figures 1, 2, 3, and 4). The treatment of probenecid and oxalate-free diet did not affect the antioxidant effect of FB.

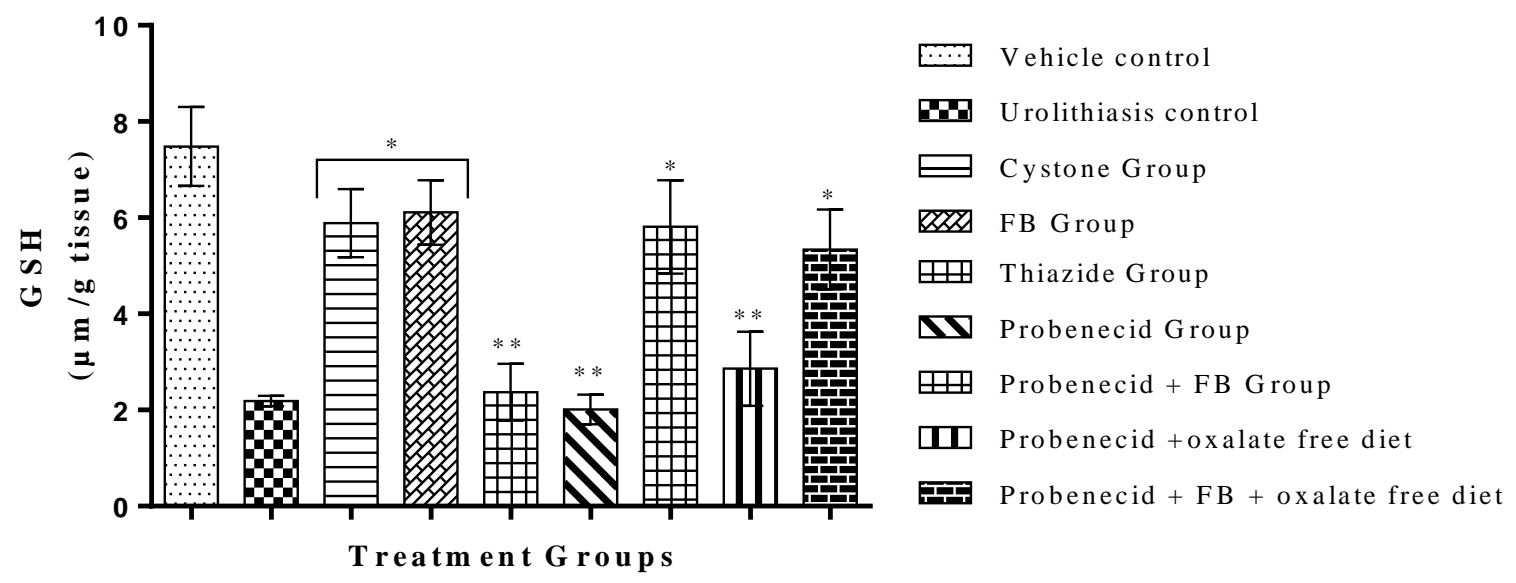

Figure 2. Effect on GSH level in kidney tissues. " $\mathrm{p}<0.001$ vs. Urolithiasis control; ${ }^{* *} \mathrm{p}<0.001$ vs. FB Group; Values are expressed as Mean $\pm \mathrm{SEM} ; \mathrm{N}=6$.

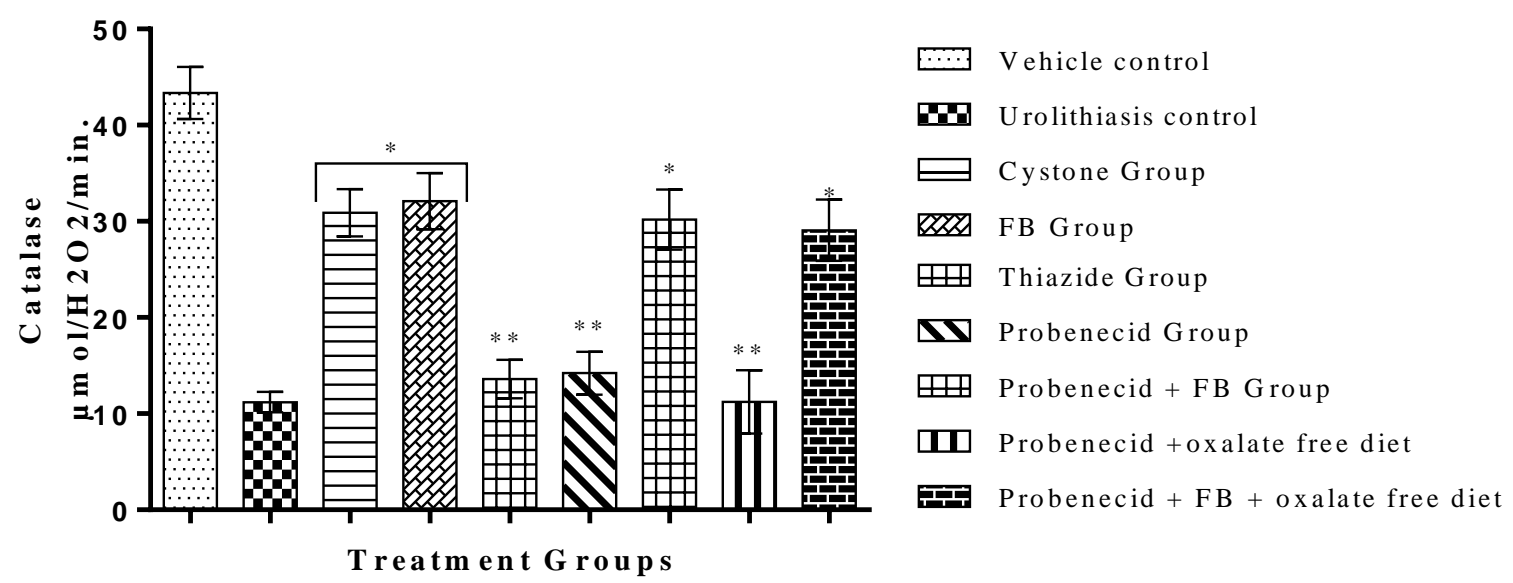

Figure 3. Effect on Catalase activity in kidney tissues. ${ }^{*} \mathrm{p}<0.001$ vs. Urolithiasis control; ${ }^{* *} \mathrm{p}<0.01$ vs. FB Group; Values are expressed as Mean $\pm \mathrm{SEM} ; \mathrm{N}=6$.

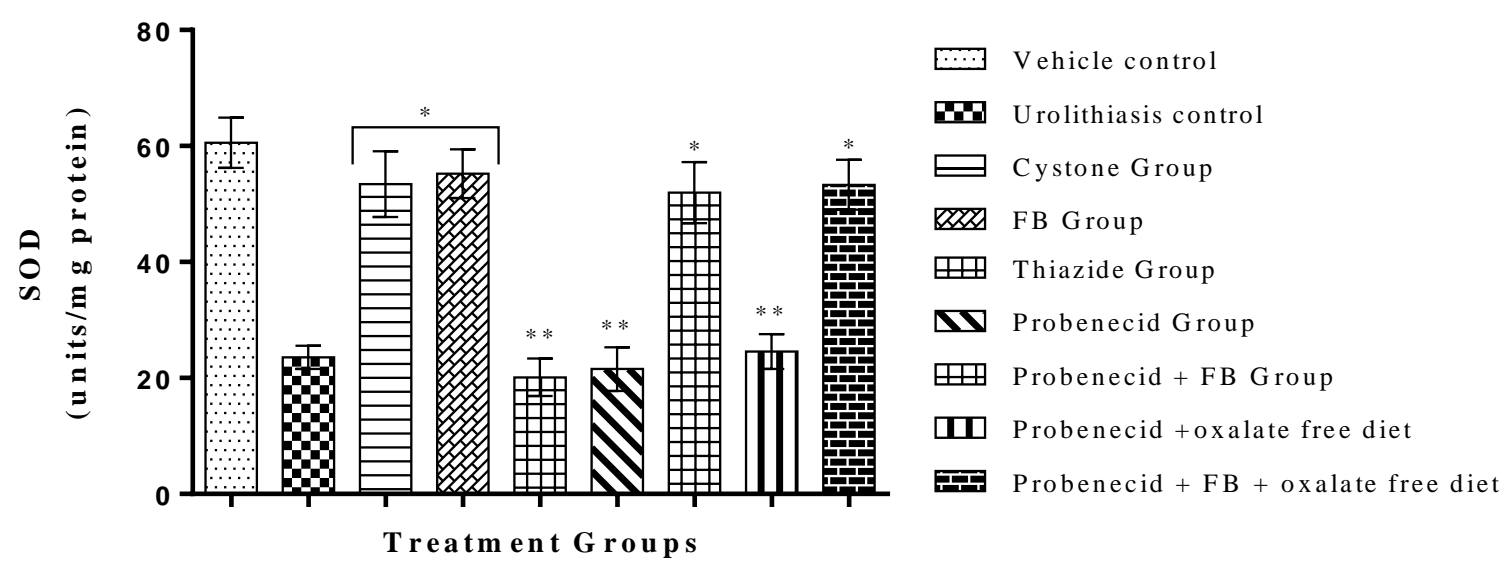

Figure 4. Effect on SOD activity in kidney tissues. ${ }^{*} \mathrm{p}<0.001$ vs. Urolithiasis control; ${ }^{* *} \mathrm{p}<0.001$ vs. FB Group; Values are expressed as Mean $\pm \mathrm{SEM} ; \mathrm{N}=6$. 


\subsection{Effect on calcium oxalate crystallization analysis in urine.}

The microscopic $(\times 100)$ examination of urine of the vehicle control group did not show any crystal, while ethylene glycol in the urolithiasis control group exhibited abundant and larger calcium oxalate crystals. Treatment with FB and cystone showed less number and small-sized crystals than urolithiasis and thiazide treated groups. The treatment of probenecid antagonized the antiurolithiasis effect of FB and showed large calcium oxalate crystals. The addition of oxalate free diet did not affect the number and size of calcium oxalate crystals, indicated dietary oxalate did not significantly contribute to urolithiasis. (Figure 5).
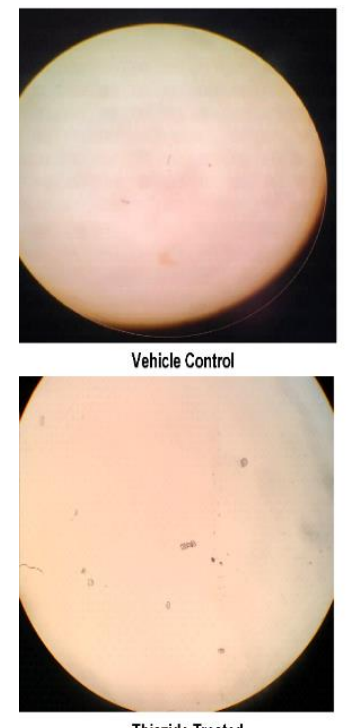

Thiazide Treated

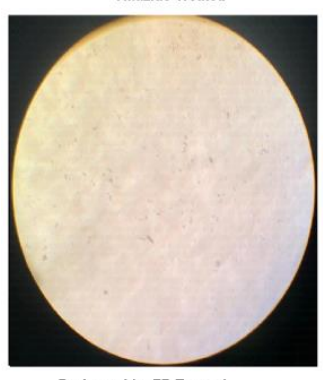

Probenecid + FB Treated

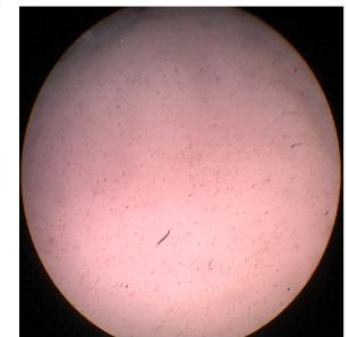

Urolithiasis Control

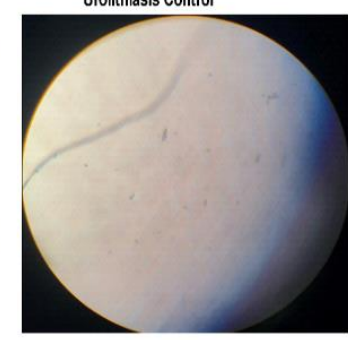

Functional Beverage Group

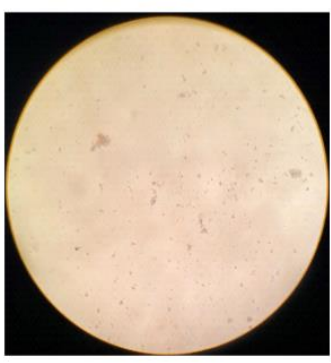

Probenecid +oxalate free diet Treated

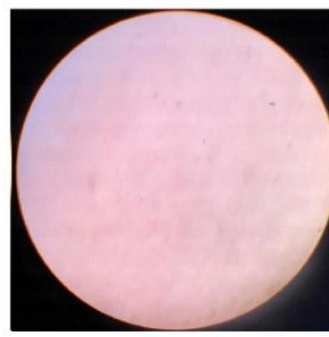

Cystone Treated

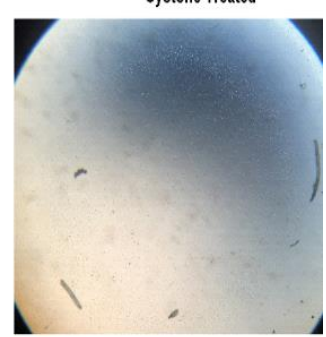

Probenecid Treated

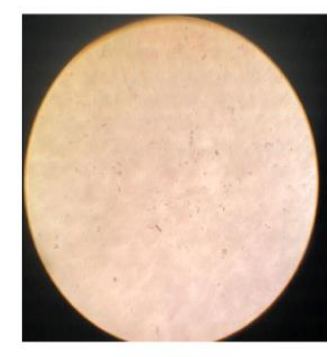

Probenecid + FB + Oxalate free diet

Figure 5. Microscopic study of calcium oxalate crystals in rat urine. CaOx crystals, viewed under a light microscope ( $\times 100)$, in $24 \mathrm{~h}$ urine from (a) Vehicle control animals shows the absence of crystals; (b) Urolithiasis group shows numerous large crystals in urine only; (c) Cystone shows the absence of crystals; (d) the Thiazide group shows few of crystals in urine; (e) the FB group shows absence of crystals in urine; (f) Probenecid group shows numerous large crystals in the urine, indicated probenecid does not have anti-urolithiasis effect; (g) Probenecid + FB group shows numerous large crystals in the urine, indicated probenecid antagonized the effect of FB on urolithiasis; (h) Probenecid + oxalate free diet group shows numerous large crystals in the urine, indicated dietary oxalate does not contribute to urolithiasis; (i) Probenecid + FB + oxalate free diet group shows numerous large crystals in the urine, indicated probenecid antagonized the effect of FB on urolithiasis.

\subsection{Effect on histological changes in the kidney.}

Histopathological sections under a light microscope showed normal architecture in-vehicle control rats. In urolithiasis, thiazide, probenecid, and probenecid + oxalate free diet animals, mild nephritis with renal tubular damage and inflammation was observed due to concomitant treatment of ethylene glycol in drinking water. Cystone, FB, and Probenecid + FB treatment with and without oxalate-free diet treated group showed less mild inflammation and nephritis and reported protection against ethylene glycol induced nephrotoxicity. It showed that FB and cystone possess 
cytoprotective effect that might be due to their antioxidant activity. Whereas thiazide and probenecid did not possess cytoprotective effect as these does not possess any antioxidant activity (Figure 6).

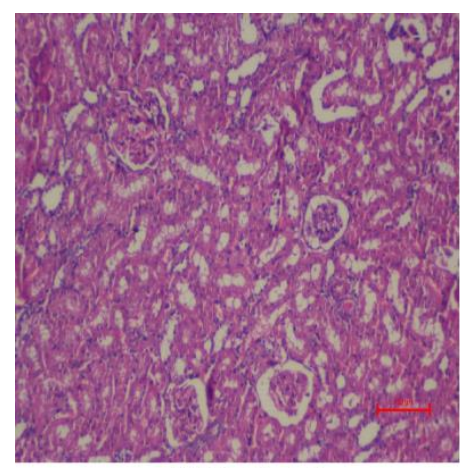

Vehicle Control

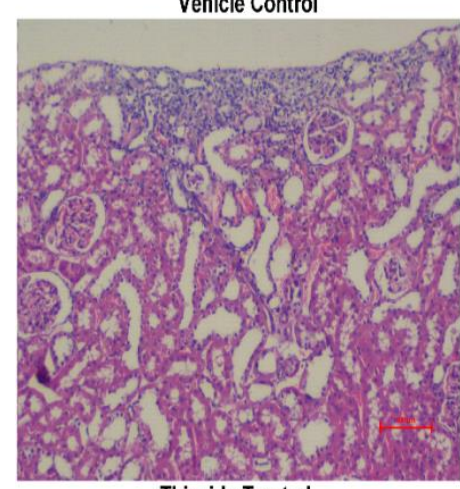

Thiazide Treated

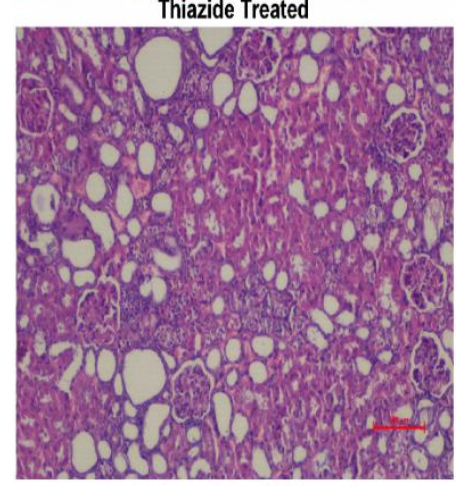

Probenecid + FB Treated

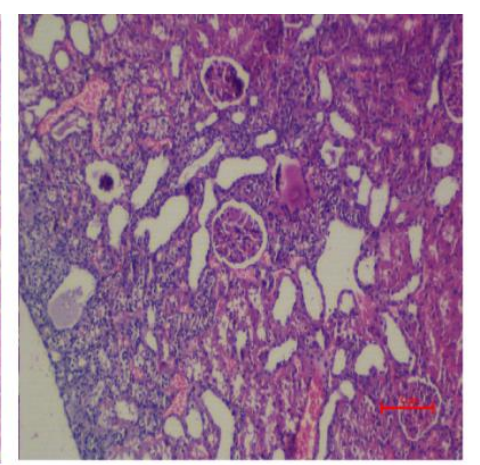

Urolithiasis Control

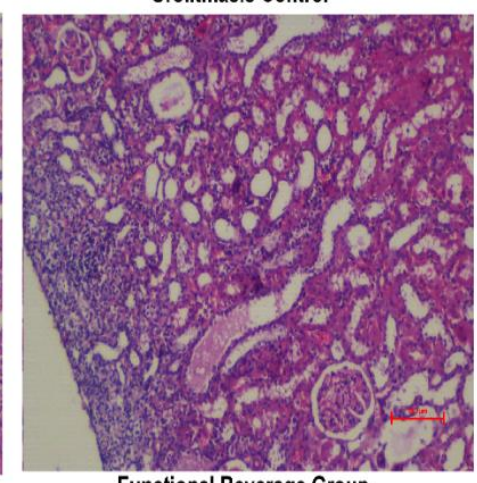

Functional Beverage Group

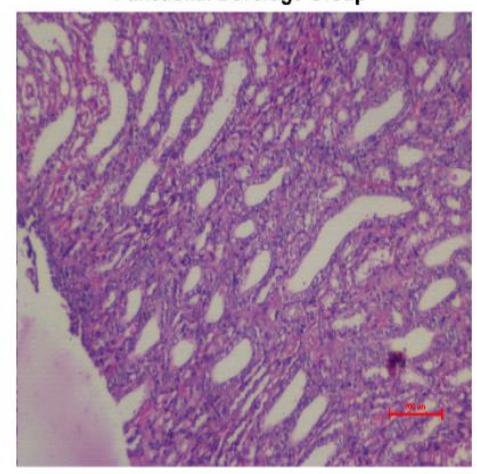

Probenecid +oxalate free diet Treated

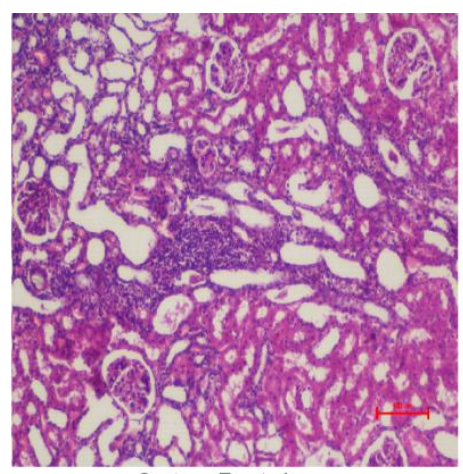

Cystone Treated

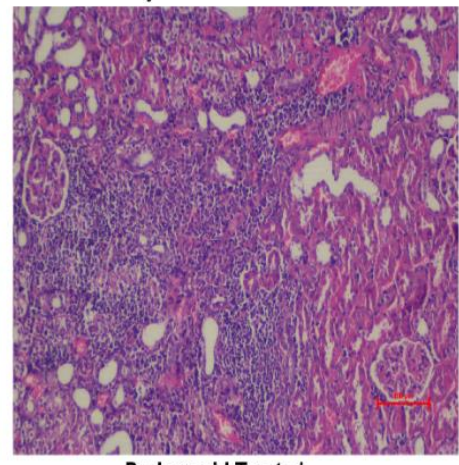

Probenecid Treated

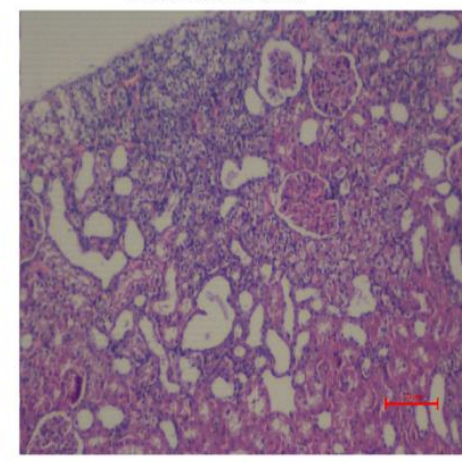

Probenecid + FB + Oxalate free diet Treated

Figure 6. Urolithiasis group (b) showed mark tubules dilation and crystal deposition due to ethylene glycol treatment if compared to the vehicle control group (a), cystone (c), FB treated (e) group, probenecid + FB treatment with and without oxalate free diet. Thiazide, Probenecid, and Probenecid + oxalate free diet showed mark tubules dilation and crystal deposition likewise urolithiasis control group due to ethylene glycol treatment. Thiazide and probenecid did

not show any effect against ethylene glycol-induced tissue injury—-magnification $\times 100$ for each section.

\subsection{Effect on phytochemical and physicochemical analysis.}

The results of the physicochemical analysis showed the specimen used for the study was not adulterated or substandard, and specifications were within limits as per Ayurvedic Pharmacopoeia of India. (Tables 3-5).

Table 3. Determination of ash values of Dolichos biflorus seed powder.

\begin{tabular}{c|l|l} 
S. No. & Ash Type & Percentage of ash \\
\hline 1 & Total ash & $8.73 \% \mathrm{w} / \mathrm{w}$ \\
\hline 2 & Acid insoluble ash & $0.51 \% \mathrm{w} / \mathrm{w}$ \\
\hline 3 & Water Soluble ash & $1.12 \% \mathrm{w} / \mathrm{w}$ \\
\hline 4 & Sulphated ash & $3.87 \% \mathrm{w} / \mathrm{w}$
\end{tabular}


Table 4. Determination of loss on drying of Dolichos biflorus.

\begin{tabular}{c|l|l} 
S. No. & Parameter & Weight $(\mathbf{g})$ \\
\hline 1 & Weight of drug + disc before drying (A) & 78.39 \\
\hline 2 & Weight of drug + disc after drying (B) & 77.9 \\
\hline 3 & $($ A-B) & 0.49 \\
\hline 4 & Loss on drying (\%) & 9.8
\end{tabular}

Table 5. Determination of extractive value of Dolichos biflorus.

\begin{tabular}{l|l|l} 
& Extract & Yield (\%) \\
\hline 1 & $50 \%$ Aqueous sodium hydroxide soluble extractive value & 1.69 \\
\hline 2 & Water soluble extractive values & 12.55 \\
\hline 3 & Methanol soluble extractive value & 4.53
\end{tabular}

The phytochemical evaluation in our study showed the presence of flavonoids, glycosides, carbohydrates, saponins, and tannins as per previous reports and Ayurvedic Pharmacopoeia of India. (Tables 6).

Table 6. Preliminary phytochemical screening of FB of Dolichos biflorus seed powder

\begin{tabular}{l|c} 
Test & FB of Dolichos biflorus \\
\hline Alkaloids & - \\
\hline Carbohydrate & + \\
\hline Glycosides & + \\
\hline Flavonoids & + \\
\hline Saponins & + \\
\hline Tannins & + \\
\hline Proteins & -
\end{tabular}

\section{Discussion}

In our present study, we explored anti-urolithiasis activity and mechanism of action of Dolichos biflorus seeds-based functional beverage. The administration of functional beverage of Dolichos biflorus seeds exhibited an anti-urolithiasis effect, possibly through Slc26 transporters. In humans and rats, oxalate metabolism is considered to be similar [28]. Chronic mild hyperoxaluria can cause calcium oxalate stone formation in both humans and rats [28]. Chronic low dose ethylene glycol (EG) administration to rats is the most commonly used animal model of urolithiasis [28].

Similarly, in this study, administration of EG in a low dose rate regimen $(1 \% \mathrm{v} / \mathrm{v})$ in drinking water for 28 days significantly induced hyperoxalemia, hyperoxaluria, and calcium oxalate renal stone. In FB and cystone treated animals significantly reduced blood and urine oxalate levels. The effect of FB on oxalate levels was consistent with published reports [29, 30]. Further, treatment of probenecid (Slc26 transporters inhibitor) has blocked the anti-urolithiasis effect FB exhibited, and these findings indicate that FB possibly produces an anti-urolithiasis effect through Slc26 transporters.

Our study findings have shown that inhibitor of Slc26 family transporters, probenecid, treatment has antagonized the effect of Dolichos biflorus based functional beverage on restoring normal oxalate level in blood urine. Slc26 family transporters facilitate oxalate secretion from the kidney and intestine and help maintain oxalate homeostasis [3]. A dramatic development in renal stone research was the observation of calcium oxalate kidney stones in Slc26a6 deficient knockout mice [31]. Similarly, human intestinal Slc26a6 activity reduction may predispose an individual to urolithiasis has been reported [32]. Probenecid treatment-induced inhibition of Slc26 family transporters has abolished the anti-urolithiasis effect of Dolichos biflorus based functional beverage. Therefore, the findings of our study suggested that bioactive compounds of Dolichos biflorus exhibit an anti-urolithiasis effect through the restoration of oxalate homeostasis by improving the activity Slc26 family transporters. This corroborates that Dolichos biflorus bioactive compounds 
possibly partly shift oxalate excretion from kidney to intestine through the increasing activity of Slc26 family transporters, thereby reducing hyperoxaluria and hyperoxalemia. Previous reports also support our findings that stated that intestinal oxalate secretion through Slc26a6 transporters might have a key role in preventing hyperoxaluria and its related calcium oxalate stone disease [31, 33].

It has long been assumed that exogenous oxalate significantly contributed to hyperoxaluria. However, the current most accepted opinion is hyperoxaluria is due to a combination of an increase in both endogenous production and intestinal absorption of oxalate [34]. Jiang et al. reported that in Slc26a6-null mice, reducing intestinal oxalate secretion increases the net amount of oxalate absorbed, thereby elevating plasma and urinary oxalate, and may contribute to urolithiasis [31]. However, we hypothesized that increased plasma and urinary oxalate is primarily due to endogenous production instead of intestinal absorption of oxalate in case of defective Slc26 transporters. The basis of our hypothesis was that individual food habits might remain almost the same throughout life; still, chances of kidney stones increase with age. However, other factors like sedentary lifestyle, less water intake, genetics, etc., may involve the pathophysiology of kidney stones [35], but food habits that are less likely to change through life will contribute to renal stones are questionable. To test this hypothesis, we evaluated the effect of oxalate free diet. An oxalateless diet did not significantly reduce urinary and plasma oxalate in probenecid-treated animals (Table 1 and 2), confirming that dietary oxalate is not primarily involved in hyperoxalemia, hyperoxaluria, and calcium oxalate urolithiasis. Our findings are also supported by previously published reports which state that plasma and urinary oxalate values were significantly higher in the Slc26a6-null than in the wild-type mice [31]. Therefore, based on our findings, we suggest that endogenous oxalate in conjunction with idiopathic or chronic reduced activity or defective Slc26 transporters due to aging results in calcium oxalate kidney stones. The functional beverage of Dolichos biflorus seeds exhibited anti-urolithiasis activity through improving the activity of Slc26 transporters.

EG treatment significantly showed low plasma, and urinary citrate, low urinary calcium as compared to the naïve control group, whereas treatment of FB and cystone restored normalization of citrate and calcium, and our findings were in accordance with previously published reports for plasma and urinary citrate $[29,30]$. EG, FB, and cystone treatment did not affect plasma, and urinary levels of creatinine, phosphorous, and urea compared to the naïve control group and suggested the safety of FB for the renal system. However, fecal oxalate level was not assessed and reported in this study. Thus, our postulation that FB of Dolichos biflorus partly shift oxalate excretion from the renal to the intestinal system shall be confirmed after assessing fecal oxalate level in conjunction with plasma and urinary oxalate levels.

\section{Conclusions}

Hyperoxaluria is due to the combination of the increase in both productions of endogenous and intestinal oxalate absorption. Based on our findings, we suggest that endogenous oxalate in conjunction with idiopathic or chronic reduced activity or defective Slc26 transporters due to aging results in calcium oxalate kidney stones. In the current study, an inhibitor of Slc26 family transporters, probenecid, treatment has antagonized the effect of Dolichos biflorus based functional beverage on the restoration of the normal level of oxalate in blood and urine. Dolichos biflorus based aqueous functional beverage being food may be devoid of adverse effects and exhibited antiurolithiasis activity through improving activity of Slc26 transporters. Thus, Dolichos biflorus seeds' functional beverage can be considered a potential candidate for treating calcium oxalate kidney stones. 


\section{Funding}

None.

\section{Acknowledgments}

The authors are grateful to the Chitkara College of Pharmacy, Chitkara University, Rajpura, Patiala, Punjab, India, for providing the necessary facilities to carry out the research work.

\section{Conflicts of Interest}

There are no conflicts of interest.

\section{References}

1. Assimos, D.G. Urolithiasis/Endourology. J. Urol. 2021, 205, 623-626, https://doi.org/10.1097/JU.0000000000001485.

2. Patle, A; Hatware, K.V; Patil, K; Sharma, S; Gupta, G. Role of Herbal Medicine in the Management of UrolithiasisA Review for Future Perspectives. J. Environ. Pathol. Toxicol. Oncol.2019, 38, 97-118, https://doi.org/10.1615/JEnvironPatholToxicolOncol.2019029075.

3. Suarez-Ibarrola, R; Hein, S; Reis, G; Gratzke, C; Miernik, A. Current and future applications of machine and deep learning in urology: a review of the literature on urolithiasis, renal cell carcinoma, and bladder and prostate cancer. World. J. Urol.2020, 38, 2329-2347, https://doi.org/10.1007/s00345-019-03000-5.

4. Markovich, D. Slc13a1 and Slc26a1 KO models reveal physiological roles of anion transporters. Physiology2012,27, 7-14, https://doi.org/10.1152/physiol.00041.2011.

5. Quhal, F; Seitz, C. Guideline of the guidelines: urolithiasis. Curr. Opin. Urol. 2021,31, 125-129, https://doi.org/10.1097/MOU.0000000000000855.

6. Veser, J; Jahrreiss, V; Seitz, C. Innovations in urolithiasis management. Curr. Opin. Urol. 2021, 31, 130-134. https://doi.org/10.1097/MOU.0000000000000850.

7. Itoh, Y; Yasui, T; Okada, A; Tozawa, K; Hayashi, Y; Kohri, K. Preventive effects of green tea on renal stone formation and the role of oxidative stress in nephrolithiasis. J. Urol.2005173, 271-275, https://doi.org/10.1097/01.ju.0000141311.51003.87.

8. Khan, A; Bashir, S; Khan, S.R. Antiurolithic effects of medicinal plants: results of in vivo studies in rat models of calcium oxalate nephrolithiasis-a systematic review. Urolithiasis. 2021, 49, 95122,https://doi.org/10.1007/s00240-020-01236-0.

9. Chakra, M.A.; Dellis, A.E.; Papatsoris, A.G.; Moussa, M. Established and recent developments in the pharmacological management of urolithiasis: an overview of the current treatment armamentarium. Expert Opin. Pharmacother.2020, 21, 85-96,https://doi.org/10.1080/14656566.2019.1685979.

10. Prosiannikov, M.Y.; Konstantinova, O.V.; Golovanov, S.A.; Anokhin, N.V.; Voitko, D.A. Possibilities of using dietary supplements with antioxidant properties in urinary stone disease. Urologiia. 2020, 4, 55-59.

11. Kant, R.; Singh, T.G.;Singh, S. Mechanistic Approach To Herbal Formulations Used For Urolithiasis Treatment. Obes. Med.2020, 19, 100266, https://doi.org/10.1016/j.obmed.2020.100266.

12. Lulat, S.I.; Yadav, Y.C.; Balaraman, R.; Maheshwari, R. Antiurolithiatic effect of lithocare against ethylene glycolinduced urolithiasis in Wistar rats. Indian J. Pharmacol.2016, 48, 78-82, https://doi.org/10.4103/02537613.174564.

13. Patel, V.B.; Acharya, N. Effect of Macrotyloma uniflorum in ethylene glycol induced urolithiasis in rats. Heliyon. 2020, 6, e04253, https://doi.org/10.1016/j.heliyon.2020.e04253.

14. Prasad, S.K.; Singh, M.K. Horse gram-an underutilized nutraceutical pulse crop: a review. J.Food Sci.Technol. 2015, 52, 2489-2499, https://doi.org/10.1007/s13197-014-1312-z.

15. Du, H.; Lei, Y.; Gao, A.N.; Sun, X.M.; Song, R.; Yu, X.D.; Deng, S.; Si, H.M.; Chen, J. Traditional Chinese medicine combined with conventional therapy for female kidney stone: A protocol for systematic review. Medicine2020,99, e19611,https://doi.org/10.1097/MD.0000000000019611.

16. Yu, K.; Zhang, P.; Xie, Z.G. A Network Pharmacology Study on the Mechanisms of the Herbal Extract, Christina Loosestrife, for the Treatment of Nephrolithiasis. Med. Sci. Monit.2020, 26, e919360, https://doi.org/10.12659/MSM.919360. 
17. Priya, F.F.; Islam, M.S. Phyllanthus emblica Linn.(Amla) — a natural gift to humans: an overview. JDMP. 2019, 5, 1-9, https://doi.org/10.11648/j.jdmp.20190501.11.

18. Visavadiya, N.P.; Narasimhacharya, A.V. Hypocholesteremic and antioxidant effects of Withania somnifera (Dunal) in hypercholesteremic rats. Phytomedicine2007,14, 136-42, https://doi.org/10.1016/j.phymed.2006.03.005.

19. Maher, S.; Choudhary, M.I.; Saleem, F.; Rasheed, S.; Waheed, I.; Halim, S.A.; Azeem, M.; Abdullah, I.B.; Froeyen, M.; Mirza, M.U.; Ahmad, S. Isolation of Antidiabetic Withanolides from Withania coagulans Dunal and Their In vitro and In Silico Validation. Biology2020, 9, 197,https://doi.org/10.3390/biology9080197.

20. Martínez, García., R.M.; Jiménez, Ortega., A.I.; Salas-González, M.D.; Bermejo, López., L.M.; RodríguezRodríguez, E. Nutritional intervention in the control of gallstones and renal lithiasis. Nutr Hosp. 2019,36, 70-74, https://doi.org/10.20960/nh.02813.

21. Rather, M.A.; Dar, B.A.; Sofi, S.N.; Bhat, B.A.; Qurishi, M.A. Foeniculum vulgare: A comprehensive review of its traditional use, phytochemistry, pharmacology, and safety. Arab. J. Chem. 2016, 9, S1574-83, https://doi.org/10.1016/j.arabjc.2012.04.011.

22. Rizwan, F.; Rashid, H.U.; Yesmine, S.; Monjur, F.; Chatterjee, T.K. Preliminary analysis of the effect of Stevia (Stevia rebaudiana) in patients with chronic kidney disease (stage I to stage III). Contemp. Clin. Trials Commun.2018, 12, 17-25, https://doi.org/10.1016/j.conctc.2018.08.007.

23. Rizwan, F.; Yesmine, S.; Banu, S.G.; Chowdhury, I.A.; Hasan, R.; Chatterjee, T.K. Renoprotective effects of stevia (Stevia rebaudiana Bertoni), amlodipine, valsartan, and losartan in gentamycin-induced nephrotoxicity in the rat model: Biochemical, hematological and histological approaches. Toxicol. Rep. 2019,6, 683-91, https://doi.org/10.1016/j.toxrep.2019.07.003.

24. Tang, G.Y.; Meng, X.; Gan, R.Y.; Zhao, C.N.; Liu, Q.; Feng, Y.B.; Li, S.; Wei, X.L.; Atanasov, A.G.; Corke, H.; Li, H.B. Health functions and related molecular mechanisms of tea components: An update review. Int. J. Mol. Sci. 2019, 20, 6196, https://doi.org/10.3390/ijms20246196.

25. Singh, T.G.; Singh H.P.; Kaur, S.; Dhiman, S. Protective effects of sesamol against cisplatin-induced nephrotoxicity in rats: A mechanistic approach. Obes. Med. 2020, 19, 100269, https://doi.org/10.1016/j.obmed.2020.100269.

26. Wagner, C.A. Etiopathogenic factors of urolithiasis. Arch Esp Urol. 2021, 74, 16-23.

27. Afkari, R.; Feizabadi, M.M.; Ansari-Moghadam, A.; Safari, T.; Bokaeian, M. Simultaneous use of oxalatedegrading bacteria and herbal extract to reduce the urinary oxalate in a rat model: A new strategy. Int. Braz. J. Urol. 2019, 45, 1249-1259, https://doi.org/10.1590/S1677-5538.IBJU.2019.0167.

28. Chaitanya, D.A.; Kumar, M.S.; Reddy, A.M.; Mukherjee, A.M.; Sumanth, M.H.; Ramesh, A. Anti urolithiatic activity of Macrotyloma uniflorum seed extract on ethylene glycol induced urolithiasis in albino rats. J. Innov. Trends Pharm. Sci.2010, 1, 216-226.

29. Patel, V.B.; Acharya, N. Anti-urolithiatic activities of macrotyloma uniflorum mediated through multiple pathway. IJPER. 2020, 54, 403-15, https://doi.org/10.5530/ijper.54.2.46.

30. Jiang, Z.; Asplin, J.R.; Evan, A.P.; Rajendran, V.M.; Velazquez, H.;Nottoli, T.P.; Binder, J.B.; Aronson, P.S. Calcium oxalate urolithiasis in mice lacking anion transporter Slc26a6. Nat. Genet.2006, 38, 474-478, https://doi.org/10.1038/ng1762.

31. Pedro, R.N.; Aslam, A.U.; Bello, J.O.; Bhatti, K.H.; Philipraj. J.; Sissoko, I.; Vasconcellos, G.S.; Trinchieri, A.; Buchholz, N. Nutrients, vitamins, probiotics and herbal products: an update of their role in urolithogenesis. Urolithiasis. 2020, 48(4), 285-301, https://doi.org/10.1007/s00240-020-01182-x.

32. Freel, R.W.; Hatch, M.; Green, M.; Soleimani, M. Ileal oxalate absorption and urinary oxalate excretion are enhanced in Slc26a6 null mice. Am. J. Physiol. Gastrointest Liver Physiol.2006, 290, G719-28, https://doi.org/10.1152/ajpgi.00481.2005.

33. Stern, K.L.; Canvasser, N.; Borofsky, M.; Gleason, V.M.; Kamphuis, G.; El Tayeb, M.M.;His, R.; Scotland, K.B. Alkalinizing Agents: A Review of Prescription, Over-the-Counter, and Medical Food Supplements. J Endourol. 2020, 34, 1-6, https://doi.org/10.1089/end.2019.0292.

34. Singh, H.P.; Singh, T.G.; Singh, R. Attenuation of Cisplatin-Induced Nephrotoxicity by p-Coumaric Acid through Peroxisome Proliferator-Activated Receptor-Gamma (PPAR- $\gamma$ ) Agonism in male Rats. Research J. Pharm. Technol. 2020, 13(11), 5270-5276, https://rjptonline.org/HTML_Papers/Research\%20Journal\%20of\%20Pharmacy\%20and\%20Technology_PID_ 2020-13-11-37.html. 
35. Singh, H.P.; Singh, T.G.; Singh, R. Sinapic acid attenuates cisplatin-induced nephrotoxicity through peroxisome proliferator-activated receptor gamma agonism in rats. J. Pharm. Bioallied Sci. 2020, 12, 146-154, https://doi.org/10.4103/jpbs.JPBS_220_19. 